\title{
EFFECT OF GROUNDWATER LEVEL ON SITE RESPONSE BEHAVIOR OF A ONE-LAYERED LIQUEFIABLE SOIL
}

\author{
Selçuk DEMİ*
}

Bolu Abant Izzet Baysal University, Department of Civil Engineering, Bolu, Turkey

\begin{tabular}{ll}
\hline Keywords & Abstract \\
\hline $\begin{array}{l}\text { Liquefiable Soil, } \\
\text { Site Response Analysis, }\end{array}$ & This study examines the effect of groundwater level ( $G W L$ ) on the seismic site \\
Numerical Model, & response behavior of a one-layered liquefiable soil using one-dimensional nonlinear \\
Groundwater Level. & of DeepSoil open-source software. The calibration of the numerical model was \\
& carried out using the results of a centrifuge experiment from the literature. The \\
& outcomes of the site response analyses were discussed in terms of peak horizontal \\
acceleration, amplification ratio, excess pore pressure ratio, shear stress-strain & behavior, and maximum lateral displacement. Also, additional numerical analyses \\
& were performed to investigate relationships between input motion intensity- $G W L$ \\
& frequency content of earthquake motion- $G W L$, and layer thickness- $G W L$. It is \\
& shown that the seismic site response behavior of the liquefiable soil is highly \\
affected by changes in groundwater levels. Moreover, depending on the location of \\
the groundwater level, the seismic behavior of the liquefiable soil may also change \\
with the increase of the input motion intensity, frequency content, and layer \\
thickness.
\end{tabular}

\section{TEK TABAKALI SIVILAŞABİLİR BİR ZEMİNİN SAHA TEPKİ DAVRANIŞI ÜZERİNE YERALTISUYU SEVIYYESİNIN ETKİII}

\section{Anahtar Kelimeler \\ Sıvılaşabilir Zemin, \\ Saha Tepki Analizi, \\ DeepSoil, \\ Sayisal Model, \\ Yeraltı Suyu Seviyesi.}

\begin{abstract}
Öz
$\mathrm{Bu}$ çalışma, yeraltı suyu seviyesinin ( $Y A S S$ ) tek tabakalı sıvılaşabilir bir zeminin sismik saha tepki davranışına olan etkisini doğrusal olmayan tek boyutlu sayısal analizler kullanılarak incelemektedir. Sıvılaşabilir zeminin tepkisi, bir açık kaynak yazılımı olan DeepSoil yardımıyla analiz edilmiştir. Sayısal modelin kalibrasyonu literatürde yer alan bir santrifüj deneyinin sonuçları kullanılarak yapılmıștır. Analiz sonuçları maksimum yatay ivme, büyütme oranı, artık boşluksuyu basıncı oranı, kayma gerilmesi-kayma şekil değiștirmesi davranışı ve maksimum yanal yer değiştirme açısından tartışılmıştır. Ayrıca, girdi deprem hareketi büyüklüğü- YASS , deprem hareketinin frekans içeriği-YASS ve tabaka kalınlığı-YASS arasındaki ilişkileri araştırmak için ek sayısal analizler yapılmıştır. Sonuçlar, zeminin sismik saha davranıșının, yeraltı su seviyesinin değişmesinden oldukça etkilendiğini göstermektedir. Ayrıca, yeraltı suyu seviyesinin konumuna bağlı olarak, sıvılaşabilir zeminin sismik davranışı giriş hareket yoğunluğunun, frekans içeriğinin ve tabaka kalınlığının artmasıyla değişebilmektedir.
\end{abstract}

Alıntı / Cite Demir, S., (2021). Effect of Groundwater Level on Site Response Behavior of a One-Layered Liquefiable Soil, Journal of Engineering Sciences and Design, 9(3), 796-808.

\begin{tabular}{l|l}
\hline Yazar Kimliği / Author ID (ORCID Number) & Makale Süreci / Article Process
\end{tabular}

\begin{tabular}{l|l}
\hline S. Demir, 0000-0003-2520-4395 & Başvuru Tarihi / Submission Date
\end{tabular}

Revizyon Tarihi / Revision Date

Kabul Tarihi / Accepted Date

Yayım Tarihi / Published Date

23.03.2021

30.05 .2021

23.06.2021

21.09.2021

\footnotetext{
* İgili yazar / Corresponding author: selcukdemir@ibu.edu.tr, +90-374-254 4831
} 


\section{Introduction}

Soil liquefaction is a phenomenon in which soil rapidly loses its shear strength due to the generation of excess pore water pressure as a result of sudden dynamic loads. This phenomenon is known as one of the major causes of significant damage during earthquakes, such as in the 1964 Niigata, 1995 Kobe, 1999 Kocaeli, 1999 Chi-Chi, 20102011 Christchurch, 2011 Tohoku, 2018 Sulawesi (Green et al., 2014; Ishihara, 1997; Sassa and Takagawa, 2019; Seed and Idriss, 1967; Tokimatsu et al., 2012; Yoshida et al., 2001; Yuan et al., 2004). Although it is impossible to preclude the occurrence of earthquakes, it is possible to reduce the liquefaction-induced damages and loss of lives by means of realistic ground motion predictions. An accurate prediction of the destructive site effects of liquefiable soils is therefore essential for the existing structures or structures in design phase.

Site effects are commonly defined as an alteration in intensity and frequency content of a seismic motion due to the propagation of waves from the bedrock to the soil surface. Earthquake-resistant design of new structures and evaluation of the seismic vulnerability of the existing structures involves prediction of their response considering local site effects (Kramer, 1996). In general, site effects are evaluated by conducting site response analysis (SRA). SRA is an important tool in earthquake engineering practice to predict the effects of soil deposits on propagated ground motion.

In the last decades, researchers and engineers have made a significant effort to understand the response of liquefiable soil deposits during strong earthquake motions. Previous case studies revealed that the characteristics of the ground motion (intensity and the frequency content) significantly alter due to the presence of liquefiable soils (Gingery et al., 2015; Matasovic and Vucetic, 1996; Sato et al., 1996; Youd and Carter, 2005; Zeghal and Elgamal, 1994; Zorapapel and Vucetic, 1994). Besides, some experimental studies focused on the site effects of multi-layered liquefiable soils and evaluated liquefiable soil behavior with respect to excess pore pressure, amplification ratio, and displacements (Adalier and Elgamal, 2005; Özener et al., 2009; Su et al., 2013; Adampira et al., 2019).

Another way to predict the site effects of liquefiable soil during an earthquake is to perform numerical site response analyses. Some investigators have numerically investigated the nonlinear site response behavior of liquefiable soils through case studies (Matasovic, 1993; Zeghal et al., 1996; Foerster and Modaressi, 2007; Zheng and Luna, 2011; Markham et al., 2016; Taghavinezhad et al., 2019). These studies have generally discussed the effect of excess pore pressure generation on acceleration-time histories or response spectra at the ground surface. In addition, Hartvigsen (2007), Kramer et al. (2011), and Montoya-Noguera and Lopez-Caballero (2016) have performed nonlinear effective stress site response studies using hypothetical soil profiles. In these studies, researchers have mainly focused on investigating the effects of excess pore water pressure on intensity and frequency content of the ground motion Das and Chakrabortty (2020) have recently performed nonlinear onedimensional numerical analyses to assess the local site effects of different soil profiles. They concluded that soil layering has an important role in the seismic site response behavior of liquefiable soils, especially when the soil is sandwiched between two non-liquefiable soil layers. Also, Adampira and Derakhshandi (2020) have studied the influence of liquefiable sublayer thickness, sub-layer depth, as well as input motion intensity on the seismic site response behavior with nonlinear parametric site response analyses. The analysis result showed that liquefiable sub-layers play a vital role on the intensity of seismic waves and earthquake-induced forces.

Despite the studies mentioned above, there is not detailed numerical study examining the site effects of the liquefiable soils based on groundwater levels ( $G W L$ ). GWL has an important role on pore water pressure distributions in saturated cohesionless soils, which may totally change site response behavior of the soil due to decreasing the shear strength or stiffness of the soil. The main goals of this study are to (a) examine the influence of $G W L$ on the seismic site response behavior of a one-layered liquefiable soil considering groundwater level changes and (b) to provide an insight for engineers to better understand the seismic mechanism of the one-layered liquefiable soil and its effects on to design of new structures or existing structures when the groundwater level was changed. A 1D nonlinear numerical model considering effective stress state was constituted using DeepSoil software (Hashash et al., 2016) to reveal site response behavior of the soil in case of different groundwater levels (the GWL was lowered from the soil surface to target depths). The results of the 1D nonlinear simulations were compared in terms of peak horizontal acceleration, amplification ratio, excess pore pressure ratio, shear stressstrain behavior, and maximum lateral displacements. Also, additional numerical analyses were performed to investigate relationships between input motion intensity- $G W L$, frequency content of earthquake motion- $G W L$, and layer thickness- GWL . 


\subsection{Simulated soil profile and properties}

In this study, a centrifuge study conducted by Taboada and Dobry (1993) was used to investigate site response behavior of the liquefiable soil (VELACS project, Model no:1). Details of the centrifuge study and properties of the sand placed in the laminar box are given in Figure 1. In the centrifuge test, a loose Nevada with a relative density $\left(D_{r}\right.$ ) of about $40 \%$ (Arulmoli et al., 1992) was used to represent the one-layered liquefiable soil. The laminar box was excited by a sinusoidal input motion with a maximum value of $0.235 \mathrm{~g}$ (Figure 2). A centrifuge acceleration of $50 \mathrm{~g}$ was applied during the test. The groundwater level ( $G W L$ ) was located at the ground surface. Pore water pressures, accelerations, and horizontal displacements were recorded during the centrifuge test at different locations.
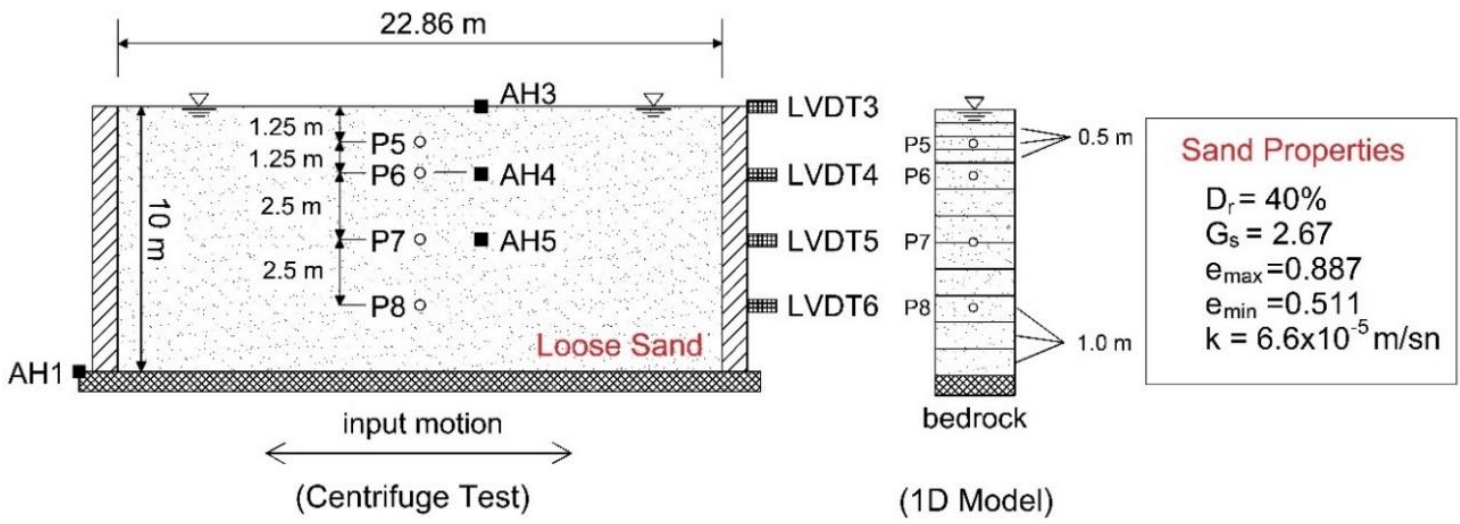

Figure 1. Instrumentation layout of the simulated centrifuge test

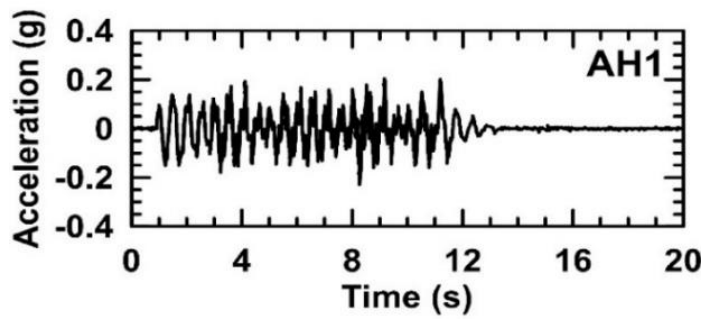

Figure 2. Input motion used in the centrifuge test

\subsection{Numerical modeling}

The open-source program DeepSoil v7.0 (Hashash et al., 2016) was utilized to perform 1D nonlinear site response analyses. Nonlinear effective stress approach was adopted in the model during DeepSoil simulations. The nonlinear stress-strain response was modeled by the pressure-dependent Modified Kondner-Zelasko (MKZ) hyperbolic-type model with non-Masing hysteretic Re/Un-loading formulation (Matasovic, 1993). Moreover, small-strain damping was represented using a frequency-independent viscous damping formulation proposed by Phillips and Hashash (2009). Darendeli (2001) model was used to determine the modulus reduction and damping curves of the soil profile. MRDF-Darandeli reduction factor was applied for the fitting procedure to obtain the fitted nonlinear curves from the Darendeli (2001) modulus reduction and damping curves.

The implied shear strength procedure proposed by Hashash et al. (2010) was applied for all DeepSoil simulations. Shear wave velocity $\left(V_{s}\right)$ of the soil profile as a function of depth $(z)$ was defined using Equation (1) that was generated from the resonant column test results conducted by Arulmoli et al. (1992) using soil's small strain shear modulus $\left(G_{\max }\right)$-mean effective stress $\left(p^{\prime}\right)$ relationship. The detail of the $V_{s}$ formulation is included in the Appendix. The soil profile was divided into 12 layers to adjust each layer's frequency greater than $30 \mathrm{~Hz}$, which is the maximum frequency criterion recommended by Hashash et al. (2016). The bottom of the soil profile was modeled as a rigid half-space. Figure 3 shows the variation of $V_{s}$, maximum frequency (Max.Freq.), and implied friction angle of the simulated soil profile.

$$
V_{s}=99.0(z)^{0.25}
$$

A pore water pressure model (Vucetic and Dobry, 1986) implemented in DeepSoil was used to generate excess pore water pressures in the soil (Equation 2). 


$$
r_{u, N}=\frac{p f N_{c} F\left(\gamma_{c}-\gamma_{t v p}\right)^{2}}{1+f N_{c} F\left(\gamma_{c}-\gamma_{t v p}\right)}
$$

where $r_{u, N}$ is residual PWP ratio after $N_{c}$ cycles and $\gamma_{c}$ is cyclic shear strain. Details of the other parameters were listed in Table 1.

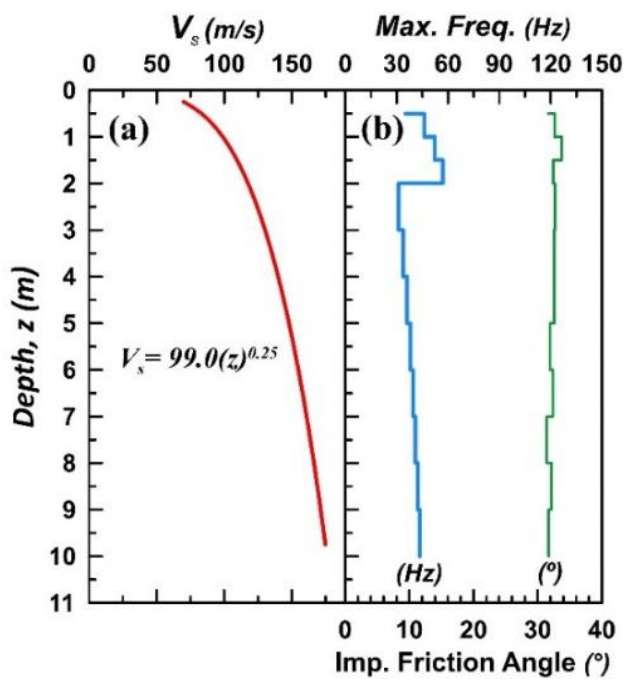

Figure 3. $V_{s}$, Max.Freq., and implied friction angle of the soil profile

DeepSoil only requires the coefficient of consolidation $\left(c_{v}\right)$ of the soil as an input value for evaluating PWP dissipation. Each layer's coefficient of consolidation was computed through Equation (3).

$$
c_{v}=\frac{k\left(1+e_{0}\right)}{\gamma_{w} a_{v}}
$$

where $k$ is the permeability, $\gamma_{w}$ is the unit weight of the water, $e_{0}$ is the initial void ratio, and $a_{v}$ is the compressibility coefficient of the soil. The coefficient of consolidation and initial void ratio were used to be $6.6 \times 10$ $5 \mathrm{~m} / \mathrm{s}$ and 0.74 , respectively (Arulmoli et al., 1992). $a_{v}$ was estimated based on laboratory studies on Nevada sand presented by Gibson (1997). It should be noted that $c_{v}$ used in DeepSoil simulations was scaled with the centrifuge acceleration of $50 \mathrm{~g}$, which makes the value of $c_{v}$ in prototype dimensions 50 times higher than in model dimensions. Table 1 shows the overall model input parameters used in DeepSoil simulations.

Table 1. Input parameters of DeepSoil used 1D simulations

\begin{tabular}{|l|c|c|l|}
\hline \multicolumn{4}{|c|}{ DARANDELI (2001) MODEL PARAMETERS } \\
\hline PARAMETER & UNIT & VALUE & REFERENCE \\
\hline Relative Density, $D_{r}$ & $\%$ & 40 & - \\
\hline Saturated unit weight, $\gamma_{\text {sat }}$ & $\mathrm{kN} / \mathrm{m}^{3}$ & 19.23 & - \\
\hline Over consolidation ratio, $O C R$ & - & 1.0 & Normally consolidated sand \\
\hline Number of loading cycles, $N$ & - & 10 & Default \\
\hline Frequency, $F r e q$ & $\mathrm{~Hz}$ & 1.0 & Default \\
\hline Plasticity index, $P I$ & $\%$ & 0 & No fine content \\
\hline Effective friction angle, $\phi^{\prime}$ & $\circ$ & 32 & (Meyerhof, 1959) \\
\hline Lateral earth pressure coefficient at rest, $K_{0}$ & - & 0.47 & (Jaky, 1944) \\
\hline \multicolumn{1}{|c|}{ EXCESS PORE WATER PRESSURE MODEL PARAMETERS } \\
\hline PARAMETER & UNIT & VALUE & REFERENCE \\
\hline Curve fitting parameter, $F$ & - & 1.7 & Mei et al. $(2018)$ \\
\hline Curve fitting parameter, $s$ & - & 1.0 & Mei et al. $(2018)$ \\
\hline Curve fitting parameter, $p$ & - & 1.15 & - \\
\hline Curve fitting parameter, $v$ & - & 1.0 & - \\
\hline $\begin{array}{l}\text { Model constant depending on 1D or 2D } \\
\text { shaking, } f\end{array}$ & - & 1.0 & - \\
\hline Volumetric threshold shear strain, $\gamma_{t v p}$ & $\%$ & 0.05 & - \\
\hline Coefficient of consolidation, $c_{v}$ & $\mathrm{~m}^{2} / \mathrm{sec}$ & Equation $(3)$ & - \\
\hline
\end{tabular}




\subsection{Validation of the model input parameters}

The ability of the model parameters to estimate nonlinear site response effects of the liquefiable soil was investigated through a comparison of simulations to measurements from the centrifuge test. The numerical results were compared with the experimental results in terms of excess pore water pressure, $5 \%$ damped spectral accelerations $\left(S_{a}\right)$, and lateral displacements, presented in Figure 4. As seen from Figure 4(a), the simulation of the onset of liquefaction and maximum excess pore pressures are very similar to those in the centrifuge test. On the other hand, DeepSoil simulations overestimate $S_{a}$ values at the soil surface (AH3) between periods of 0.01 to $1.0 \mathrm{~s}$. Nonetheless, a better match with the centrifuge measurements at $5.0 \mathrm{~m}$ depth is seen from DeepSoil simulations as compared to the soil surface records (Figure 4b). Lastly, lateral displacement-time history results at the soil surface and $7.5 \mathrm{~m}$ depth obtained from centrifuge test results and numerical simulations are compared in Figure 4(c). In general, the magnitude of lateral displacements at each time step is consistent with the experimental measurements.

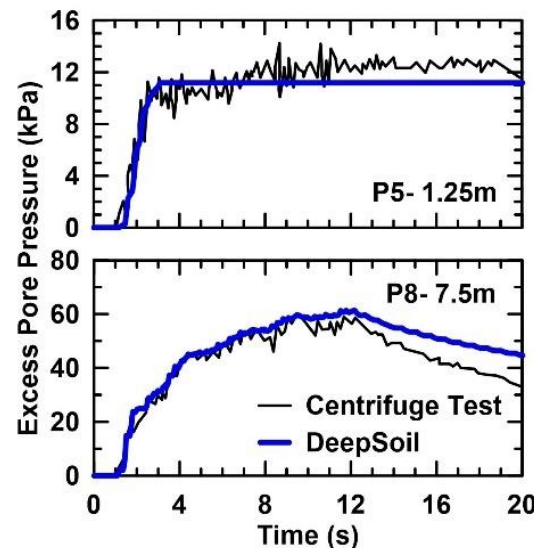

(a)

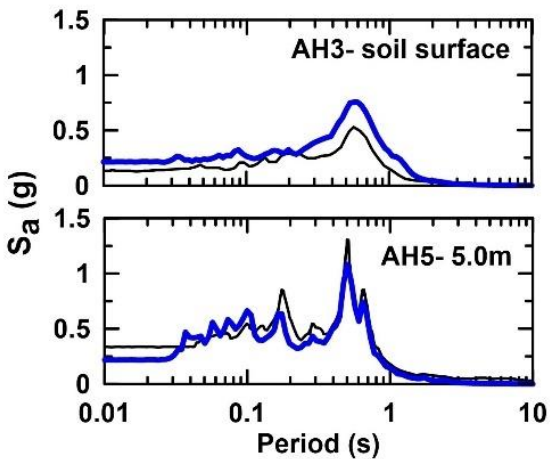

(b)

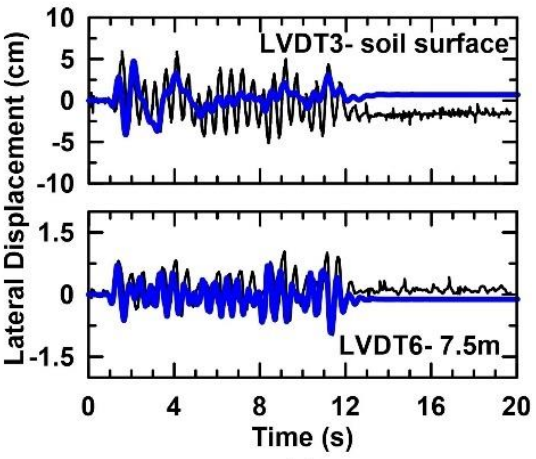

(c)

Figure 4. Comparison of (a) excess pore pressures, (b) response spectra ( $5 \%$ damped), and (c) lateral displacements of centrifuge test and numerical simulation results at various locations

\section{Results}

In this section, a parametric study was conducted considering various groundwater levels and the influence of groundwater level $(G W L)$ on the site response behavior of the one-layered liquefiable soil was investigated in terms of peak horizontal acceleration $\left(P G A_{\max }\right)$, amplification ratio $\left(A_{r}\right)$, excess pore pressure ratio $\left(r_{u}\right)$, shear stress-shear strain ( $S S$ ) behavior, and maximum lateral displacement at the ground surface $\left(L_{d, \max }\right)$. Furthermore, additional numerical analyses were performed for evaluating relationships between input motion intensity $\left(a_{\max }\right)-G W L$, frequency content $\left(f_{p}\right)-G W L$, and layer thickness $(H)-G W L$.

A group of five groundwater levels was selected during nonlinear 1D simulations, $G W L=0,1,2,4$, and $6 \mathrm{~m}$. Here, $G W L=0$ corresponds fully saturated soil profile, which means that $G W L$ locates at the ground surface. Besides, the input motion given in Figure 2 was scaled to $a_{\max }=0.05 \mathrm{~g}, 0.1 \mathrm{~g}, 0.2 \mathrm{~g}$ and $0.4 \mathrm{~g}$ to evaluate $a_{\max }-G W L$ relationship. During $a_{\max }-G W L$ simulations, frequency content and layer thickness of the soil were kept constant ( $f_{p}=2.0 \mathrm{~Hz}$ and $\left.H=10 \mathrm{~m}\right)$. Similarly, four earthquake motions with different predominant frequencies $\left(f_{p}=0.29\right.$, $1.10,4.83,7.22 \mathrm{~Hz}$, and $H$ and $a_{\max }$ fixed to $10 \mathrm{~m}$ and $\left.0.3 \mathrm{~g}\right)$ and four different layer thicknesses $(H=5,7,10,20 \mathrm{~m}$, and $a_{\max }$ and $f_{p}$ fixed to $0.235 \mathrm{~g}$ and $2.0 \mathrm{~Hz}$ ) were considered to assess the other relationships between $f_{p}-G W L$, and $H-G W L$. Details of the parametric study are listed in Table 2. The acceleration-time histories and corresponding Fourier amplitudes of the selected earthquake motions are given in Figure 5.

Table 2. Details of the parametric study

\begin{tabular}{|c|c|c|}
\hline SYMBOL & PARAMETRIC VALUE & CONSTANTS \\
\hline $\boldsymbol{G} \boldsymbol{W} \boldsymbol{L}$ & $0,1,2,4,6 \mathrm{~m}$ & $f_{p}=2.0, \mathrm{H}=10, a_{\max }=0.235$ \\
\hline $\boldsymbol{a}_{\boldsymbol{m a x}}$ & $0.05,0.1,0.2,0.4 \mathrm{~g}$ & $f_{p}=2.0, \mathrm{H}=10$ \\
\hline $\boldsymbol{f}_{\boldsymbol{p}}$ & $0.29,1.1,4.83,7.22 \mathrm{~Hz}$ & $a_{\max }=0.3, \mathrm{H}=10$ \\
\hline $\boldsymbol{H}$ & $5,7,10,20 \mathrm{~m}$ & $a_{\max }=0.235, f_{p}=2.0$ \\
\hline
\end{tabular}



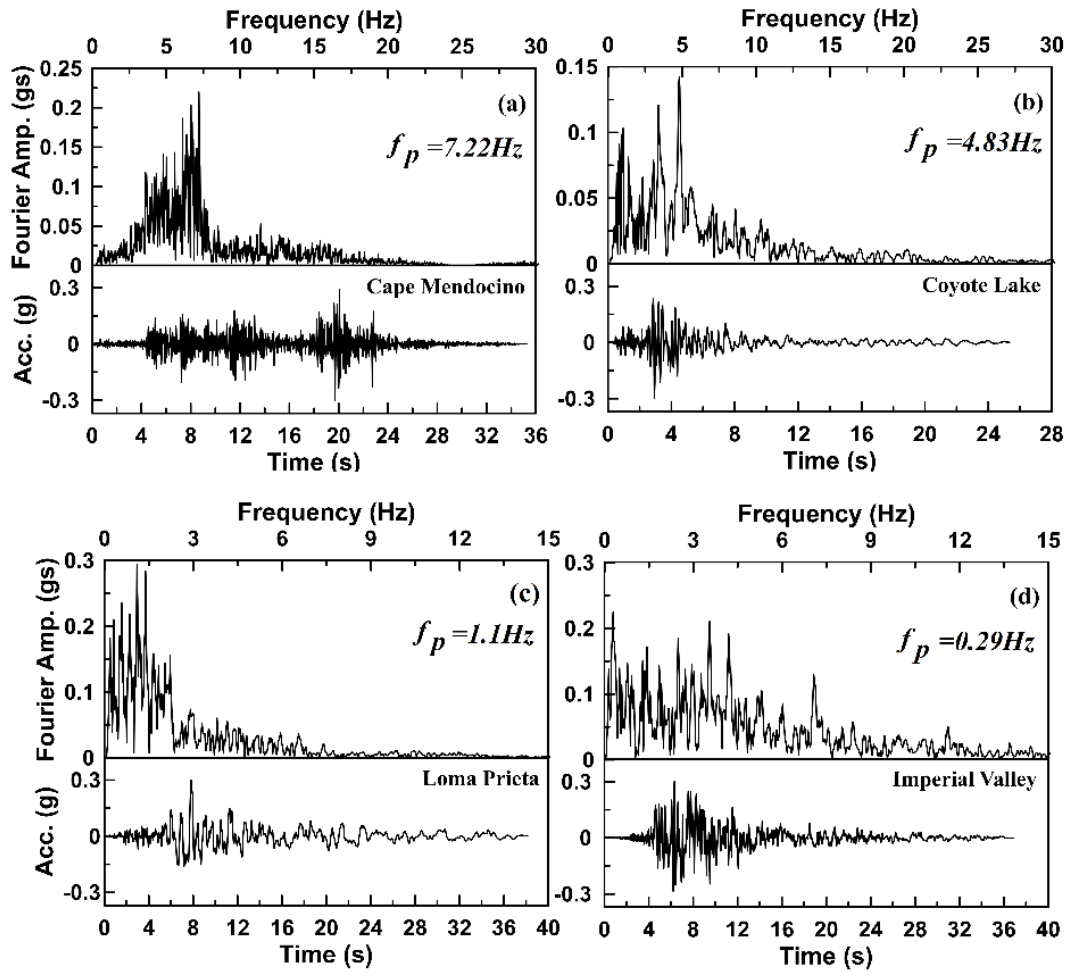

Figure 5. Fourier amplitudes of the earthquake motions (a) CM, (b) CL, (c) LP, and (d) IV

\subsection{Analysis results of $P G A_{\max }, A_{r} r_{u}, S S$, and $L_{d, \max }$}

\subsubsection{Variations in $P G A_{\max }$ and $A_{r}$}

The effects of groundwater level on the peak horizontal accelerations are examined, as shown in Figure 6. According to the figure, as the groundwater level increases, $P G A_{\max }$ values increase as well through the soil profile. When the groundwater level is located above $2.0 \mathrm{~m}$, the values of $P G A_{\max }$ at the ground surface are deamplified however, $P G A_{\max }$ values are amplified in cases of $G W L \geq 2.0 \mathrm{~m}$.

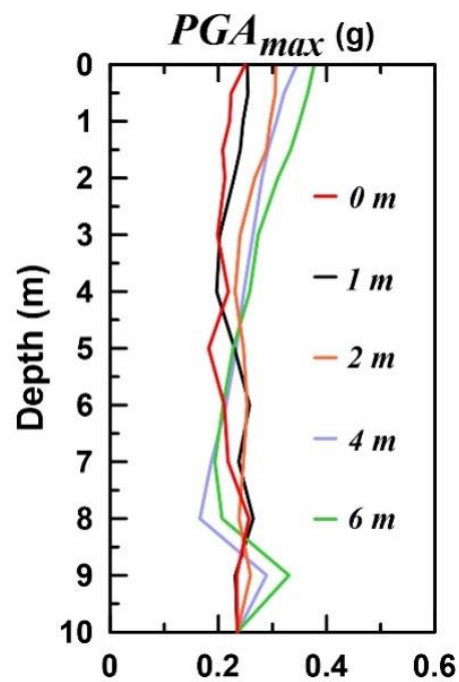

Figure 6. Variation of peak horizontal accelerations with ground water level.

Variation of spectral accelerations in a periodic range is presented in Figure 7 using amplification ratio $\left(A_{r}\right)$. Here $A_{r}$ is the ratio of the spectral acceleration of the soil surface to the spectral acceleration of base input motion. As shown, the amplification ratio is very similar for all $G W L$ values at periods $1.0-10 \mathrm{sec}$, implying the variation of groundwater level has little effect on $A_{r}$ values. It is seen that from Figure 7, the effect of $G W L$ on the $A_{r}$ values are more remarkable at short periods $(\mathrm{T}<0.5 \mathrm{sec})$, whereas for long periods $(\mathrm{T}>0.5 \mathrm{~s})$ the influence is less 
noticeable. The increase of $G W L$ value leads to some increase in $A_{r}$ values at periods $\mathrm{T}<0.5 \mathrm{sec}$. Moreover, $A_{r}$ values increase conspicuously at about $\mathrm{T}=1.0 \mathrm{sec}$ and reach approximately $A_{r}=3.5-4.0$.

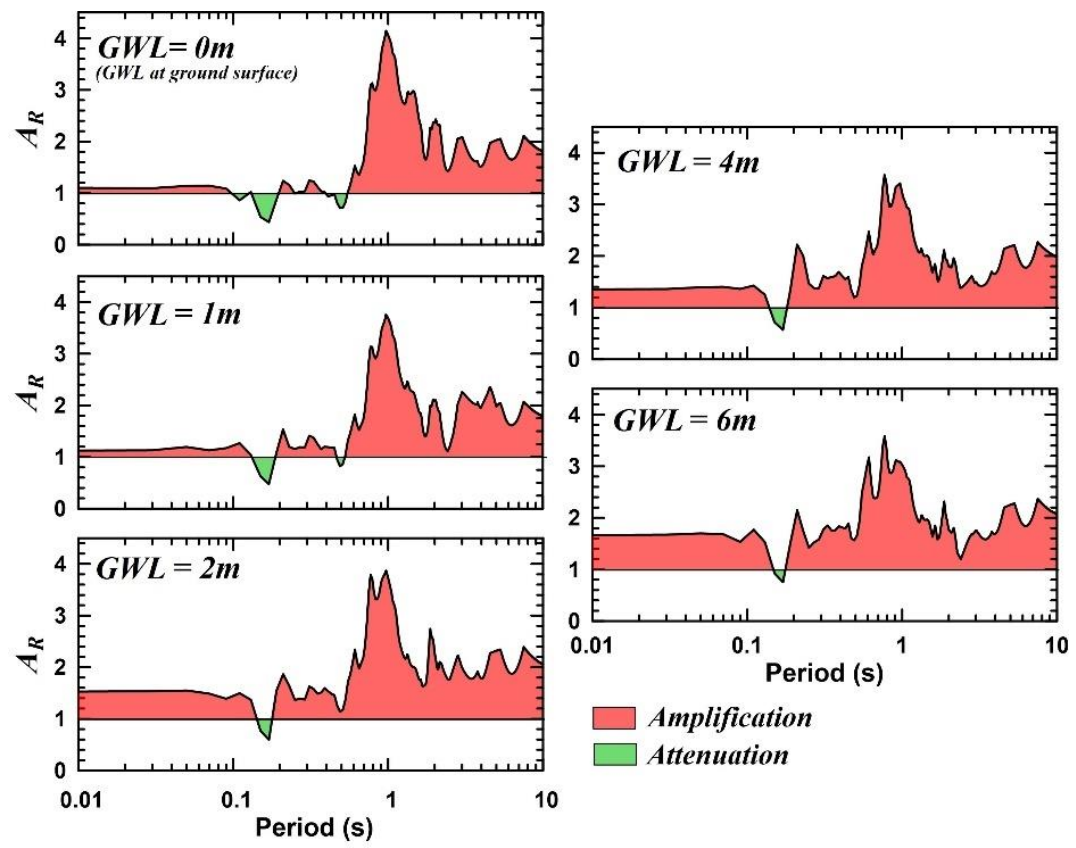

Figure 7. Change of amplification ratios with groundwater level.

\subsubsection{Variations in $r_{u}$}

The variation of $r_{u}$ values at 2.5, 5 and 7.5m depths are presented in Figure 8 for different $G W L$ values. As expected, larger pore water pressure ratios $\left(r_{u}\right)$ are predicted when using lower ground water levels. $r_{u}$ values reach nearly $1.0\left(r_{u}=0.8-1.0\right)$ for all depths in the case of $G W L=0$ and $G W L=1.0 \mathrm{~m}$, indicating soil liquefaction. Besides, maximum $r_{u}$ values decrease with increasing $G W L$ and soil depth.
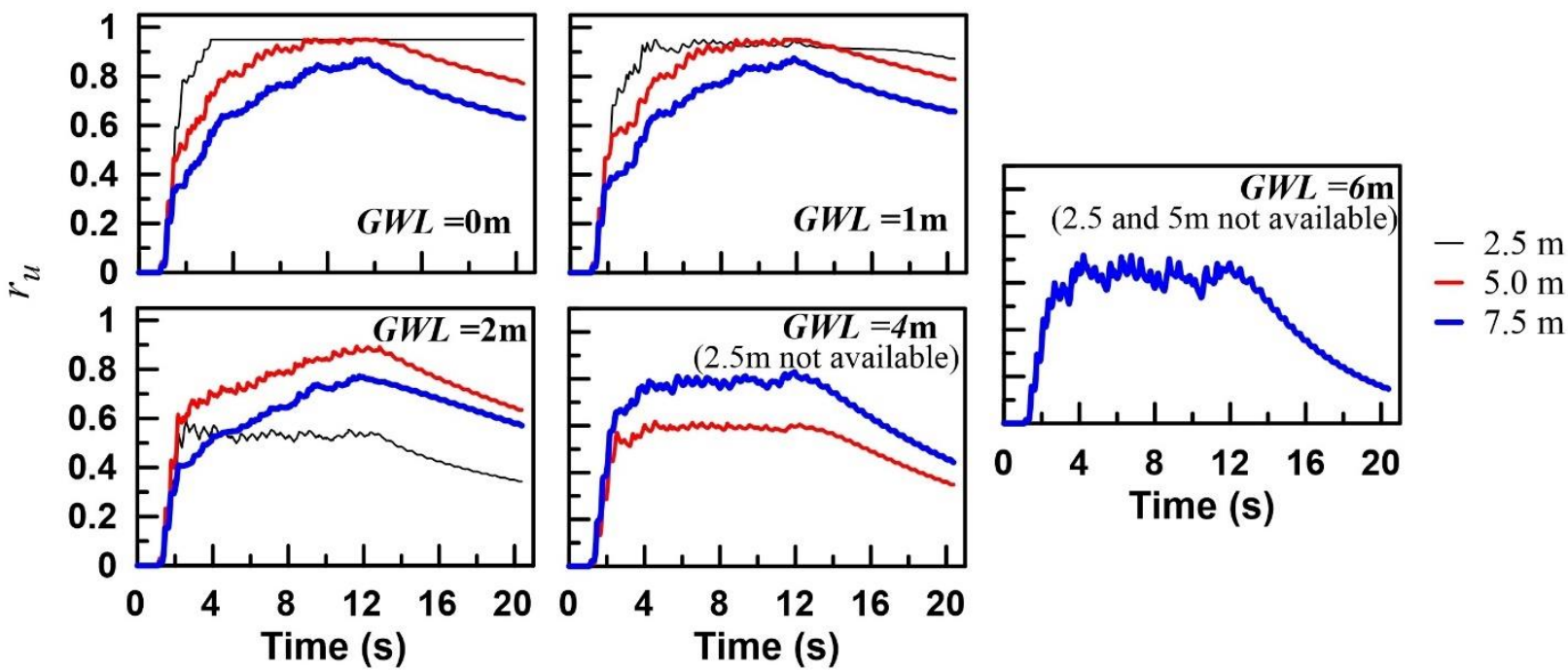

Figure 8. Simulated $r_{u}$-time histories at different depths.

\subsubsection{Variations in $S S$, and $L_{d, \max }$}

Shear stress-strain ( $S S$ ) behavior of the soil at three depths and maximum lateral displacements $\left(L_{d, \max }\right)$ at the ground surface with different $G W L$ values are shown in Figures 9 and 10, respectively. It is seen that from the hysteresis shear stress-shear strain loops of the soil given in Figure 9, the increase of $G W L$ value leads to a decrease in the shear strain level. For instance, when $G W L$ increases from 0 to $6 \mathrm{~m}$, the maximum shear strain 
reduces from $2 \%$ to $0.8 \%$ at 2.5 depth. This is expected because fully saturated liquefiable soils exhibit more nonlinearity as compared to unsaturated or dry soils when the soil layers are subjected to strong input motions. On the other hand, similar $S S$ responses are observed at $7.5 \mathrm{~m}$ depth for all $G W L$ values.

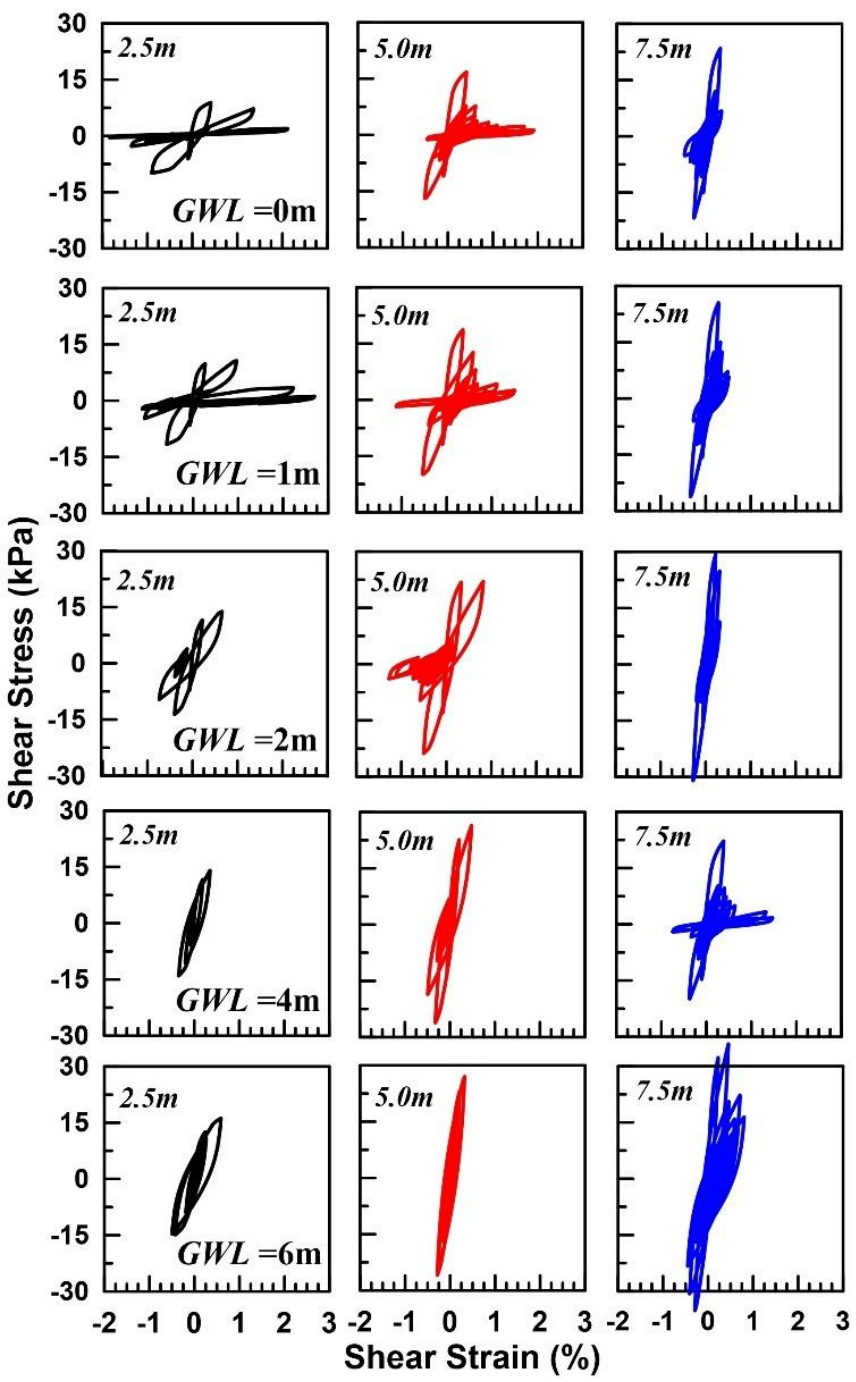

Figure 9. Numerically computed shear stress-strain loops at different depths.

Figure 10 shows $L_{d, \max }$ values at the ground surface according to the increase of $G W L$ values. In Figure 10, when the $G W L$ values are increased, lower lateral soil displacements are observed. The value of $L_{d, \max }$ decreased by approximately $30 \%$ as the $G W L$ value increased from $0 \mathrm{~m}$ to $6 \mathrm{~m}$.

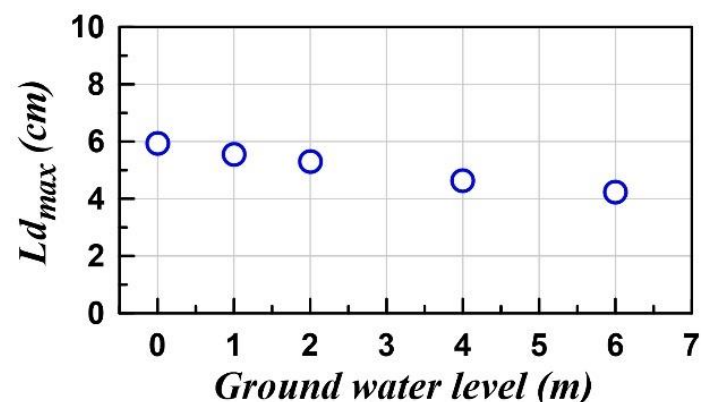

Figure 10. Change of maximum lateral displacements at the ground surface with groundwater level.

\subsection{Analysis of the relationships between $a_{\max }-G W L, f_{p}-G W L$, and $H-G W L$.}

In this section, numerical analyses were performed with two groundwater levels ( $G W L=0$ and $G W L=10$ ) to investigate the behavior between $a_{\max }-G W L, f_{p}-G W L$, and $H-G W L$. Here, $G W L=0$ and $G W L=10$ represent 
saturated and dry soil cases, respectively. Simulation results were evaluated in terms of $P G A_{\max }$ and $L_{d, \max }$ values at the ground surface, and maximum shear strain value developed in the soil profile.

\subsubsection{Relationship between $a_{\max }$ and $G W L$}

Figure 11 shows variations of $P G A_{\max }, L_{d, \max }$, and maximum shear strain values predicted in saturated $(G W L=0)$ and dry soils $(G W L=10)$ versus the input motion intensity $\left(a_{\max }\right)$. In general, as the input motion intensity increases $P G A_{\max }, L_{d, \max }$, and maximum shear strain values increase both for saturated and dry soil cases. Numerical predictions obtained from saturated soil case exhibit similar responses as compared to dry soil in terms of $P G A_{\max }$ during weak input motion intensities ( $a_{\max }=0.05$ and $0.1 \mathrm{~g}$ ). However, $P G A_{\max }$ values depart noticeably with $a_{\max }$ increase. As the groundwater level is lowered from the soil surface to the base, seismically induced horizontal accelerations at the ground surface are increased. For example, $P G A_{\max }$ values increase by about two times when $a_{\max }=0.4 \mathrm{~g}$. Furthermore, when the soils are shaken under the strong input motion intensities, soils tend to deamplification behavior, especially in the case of saturated soil. It is also noticeably seen from Figure 11 that the increase of $a_{\max }$ leads to an increase in the $L_{d, \max }$ and maximum shear strain level. This is expected because the soils exhibit nonlinear behavior when soil layers are subjected to strong input motion intensities, which leads to the development of large lateral displacements and shear strains in the soil. In addition, the saturated soil shows more lateral displacements and shear strains than the dry soil as $a_{\max }$ increases due to the change of effective stresses.
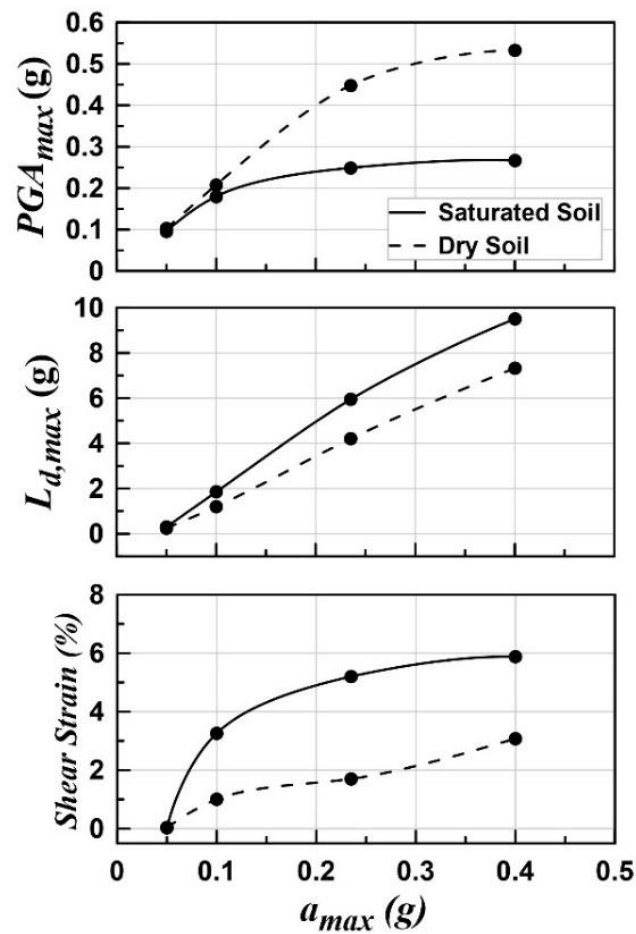

Figure 11. Effect of $a_{\max }$ and $G W L$ values on $P G A_{\max }, L_{d, \max }$, and maximum shear strains

\subsubsection{Relationship between $f_{p}$ and $G W L$}

Figure 12 displays the $P G A_{\max }, L_{d, \max }$, and maximum shear strains in the soil computed during four earthquake motions. It is clearly seen that frequency contents (predominant frequencies) of the earthquake motions significantly influence peak horizontal accelerations, lateral displacements, and strain behavior of the soil. In accordance with the results given in Figure 11, predicted values of $P G A_{\max }$ from the dry soil are larger than those in the saturated soil. In general, as the $G W L$ lowers and $f_{p}$ increases, $P G A_{\max }$ values decrease. Decreasing the predominant frequency of the earthquake motions result in large variations of the maximum shear strains and lateral displacements in the saturated soil. Larger shear strains are predicted from saturated soil simulations when using input motions with lower frequency content. Besides, the influence of $f_{p}$ values on the $L_{d, \max }$ and maximum shear strains are negligible for dry soil case. 

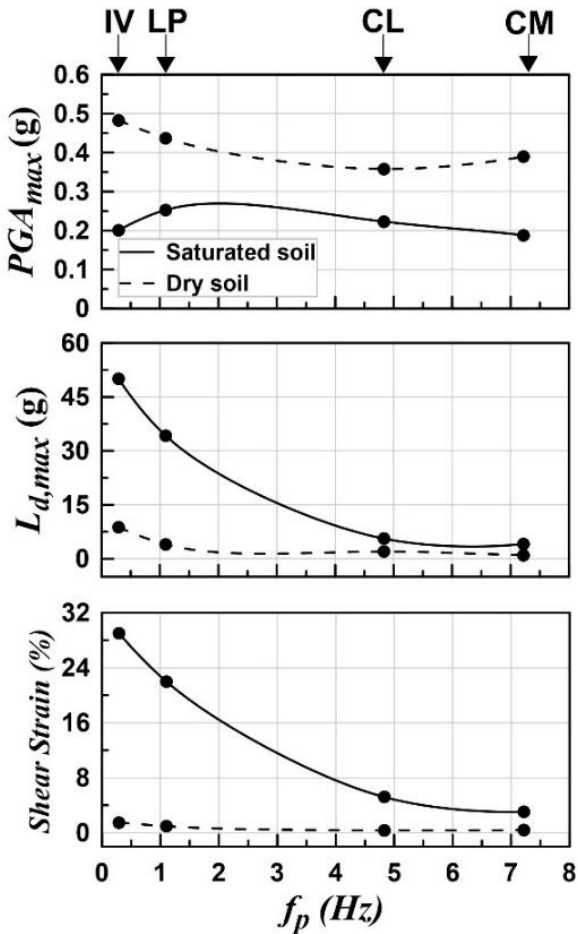

Figure 12. Effect of $f_{p}$ and $G W L$ values on $P G A_{\max }, L_{d, \max }$, and maximum shear strains

\subsubsection{Relationship between $H$ and $G W L$}

Figure 13 presents the effect of layer thickness $(H)$ and groundwater level on the $P G A_{\max }, L_{d, \max }$, and maximum shear strain values. The increase of the soil layer thickness leads to a slight decrease on $P G A_{\max }$ values. All dry soil layers resulted in higher $P G A_{\max }$ values than the saturated layers due to the change in the effective stress of the soils. Comparisons of the $L_{d, \max }$ and maximum shear strain variations in the dry and saturated soils are also shown in Figure 13. It is seen that $L_{d, \max }$ and maximum shear strain values in the dry soil case are smaller than saturated soil case. Furthermore, the trend of $L_{d, \max }$ and maximum shear strain curves are almost similar with $\mathrm{H}$ increases for dry and saturated soils. $L_{d, \max }$ values increase noticeably as $H$ increases, while the change of maximum shear strains with the increment of $H$ is limited both for dry and saturated soil cases.
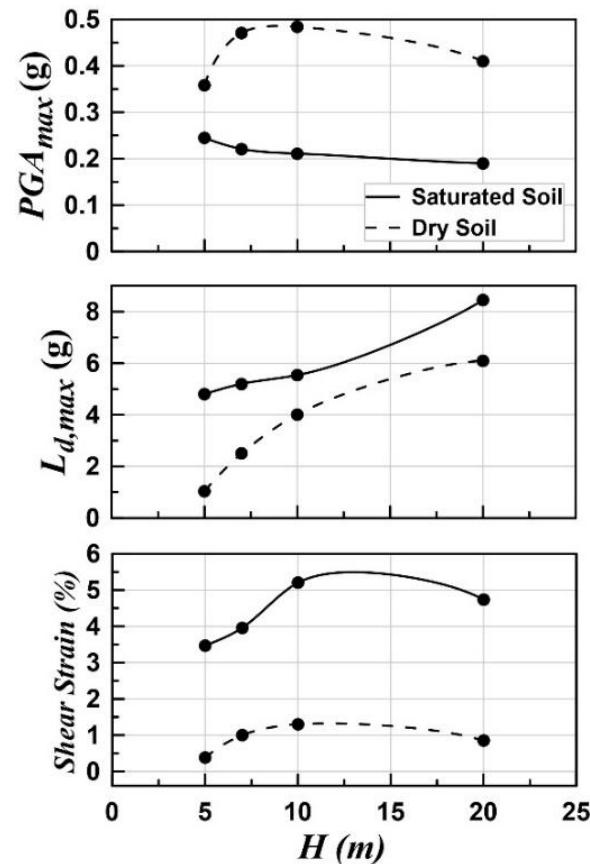

Figure 13. Effect of $H$ and $G W L$ values on $P G A_{\max }, L_{d, \max }$, and maximum shear strains 


\section{Conclusions}

1D nonlinear numerical analyses were performed in this study to investigate the effect of different groundwater levels on the site response behavior of a one-layered liquefiable soil. The following conclusions can be drawn from the results:

The peak horizontal accelerations throughout the soil profile were increased, and earthquake-induced horizontal accelerations at the ground surface were amplified with lowering groundwater level from the soil surface to the base. The amplification was seen more clearly at short periods $(\mathrm{T}<0.5 \mathrm{sec})$, considering the amplification ratio. On the contrary, excess pore pressure ratios, maximum shear strains and maximum lateral displacements became even less when groundwater levels lowered deeper depths. This mechanism is directly related to the change in the effective stress of the liquefiable soil due to the variation of the groundwater level.

As the input motion intensity increases, $P G A_{\max }, L_{d, \max }$, and maximum shear strain values increase both for saturated and dry soil cases. When the soils were shaken under the strong input motion intensities, soils tend to deamplification behavior, especially in the case of saturated soil. Saturated liquefiable soils behave like a seismic isolator under strong seismic loads and significantly reduce the horizontal accelerations affecting the ground surface (Kokusho, 2014). Although this behavior was seen to be a positive contribution to the seismic site response effect of the liquefiable soils, shear strains and lateral displacements obtained from the liquefiable soil case were found higher than the dry soil case. The frequency content of earthquake motion was considerably altered the site response behavior of the saturated liquefiable soil. Especially large shear strains and lateral displacements were observed for the saturated soil $(G W L=0)$ during earthquake motions with low predominant frequency. On the other hand, the effect of predominant frequency on the site response behavior was negligible for dry soil case ( $G W L=10)$. The results indicated that the effect of the layer thickness $(H)$ appeared to be lower as compared to $a_{\max }$ and $f_{p}$ values both for saturated and dry soil cases.

It is thought that this study provides a guide for designers and geotechnical engineers to better understand the seismic mechanism of the one-layered liquefiable soil and its effects to superstructures at the ground surface when the groundwater level changes.

\section{Conflict of Interest}

No conflict of interest was declared by the author.

\section{References}

Adalier, K., Elgamal, A., 2005. Liquefaction of Over-Consolidated Sand: A Centrifuge Investigation. Journal of Earthquake Engineering, 9:127-150.

Adampira, M., Derakhshandi, M., Ghalandarzadeh, A. 2019. Experimental Study on Seismic Response Characteristics of Liquefiable Soil Layers. Journal of Earthquake Engineering, https://doi.org/10.1080/13632469.13632019.11568930.

Adampira, M., Derakhshandi, M., 2020. Influence of a Layered Liquefiable Soil on Seismic Site Response Using Physical Modeling and Numerical Simulation. Engineering Geology, 266:105462.

Arulmoli, K., Muraleetharan, K.K., Hossain, M.M., Fruth, L.S., 1992. VELACS: Verification of Liquefaction Analyses by Centrifuge Studies, Laboratory Testing Program. Soil Data Report.

Darendeli, M.B., 2001. Development of a New Family of Normalized Modulus Reduction and Material Damping Curves. PhD. Thesis, In: Civil Engineering, University of Texas at Austin.

Das, A., Chakrabortty, P., 2020. Influence of Motion Energy and Soil Characteristics on Seismic Ground Response of Layered Soil. International Journal of Civil Engineering, 1-20.

Foerster, E., Modaressi, H., 2007. Nonlinear Numerical Method for Earthquake Site Response Analysis II-Case Studies. Bulletin of Earthquake Engineering, 5:325-345.

Gibson, A.D., 1997. Physical Scale Modeling of Geotechnical Structures at One-G. PhD. Thesis, In: California Institute of Technology.

Gingery, J.R., Elgamal, A., Bray, J.D., 2015. Response Spectra at Liquefaction Sites During Shallow Crustal Earthquakes. Earthquake Spectra, 31:2325-2349.

Green, R.A., Cubrinovski, M., Cox, B. et al., 2014. Select Liquefaction Case Histories from the 2010-2011 Canterbury Earthquake Sequence. Earthquake Spectra, 30, 131-153.

Hartvigsen, A.J., 2007. Influence of Pore Pressures in Liquefiable Soils on Elastic Response Spectra. PhD. Thesis, In: University of Washington.

Hashash, Y., Phillips, C., Groholski, D.R., 2010. Recent Advances in Non-Linear Site Response Analysis. In: 5th Int. Conf. in Recent Advances in Geotechnical Earthquake Engineering and Soil Dynamics, Missouri Univ. of Science and Technology, Rolla, MO.

Hashash, Y.M., Musgrove, M., Harmon, J., et al., 2016. DEEPSOIL 7.0 User Manual. Urbana, IL, Board of Trustees of University of Illinois at Urbana-Champaign.

Ishihara, K., 1997. Terzaghi Oration: Geotechnical Aspects of the 1995 Kobe Earthquake. In: Proceedings of the International 
Conference on Soil Mechanics and Foundation Engineering-International Society for Soil Mechanics and Foundation Engineering, AA Balkema, pp. 2047-2074.

Jaky, J., 1944. The Coefficient of Earth Pressure at Rest. Journal of the Society of Hungarian Architects and Engineers, 355-358.

Kramer, S.L., 1996. Geotechnical Earthquake Engineering. Upper Saddle River, NJ: Pearson.

Kramer. S., Hartvigsen, A., Sideras, S., Ozener, P., 2011. Site Response Modeling in Liquefiable Soil Deposits. In: 4th IASPEI/IAEE International Symposium: Effects of Surface Geology on Seismic Motion, pp. 1-12.

Kokusho, T., 2014. Seismic Base-Isolation Mechanism in Liquefied Sand in Terms of Energy. Soil Dynamics and Earthquake Engineering, 63:92-97.

Markham, C.S., Bray, J.D., Macedo, J., Luque, R., 2016. Evaluating Nonlinear Effective Stress Site Response Analyses Using Records from the Canterbury Earthquake Sequence. Soil Dynamics and Earthquake Engineering, 82:84-98.

Matasovic, J., Vucetic, M., 1996. Analysis of Seismic Records from the Wildlife Liquefaction Site. In: Proc. 11th World Conf. Earthquake Engineering.

Matasovic, N., 1993. Seismic Response of Composite Horizontally-Layered Soil Deposits. PhD. Thesis, In: University of California.

Mei, X., Olson, S.M., Hashash, Y.M., 2018. Empirical Porewater Pressure Generation Model Parameters in 1-D Seismic Site Response Analysis. Soil Dynamics and Earthquake Engineering, 114:563-567.

Meyerhof, G.G., 1959. Compaction of Sands and Bearing Capacity of Piles. Transactions of the American Society of Civil Engineers, 126:1292-1322.

Montoya-Noguera, S., Lopez-Caballero, F., 2016. Effect of Coupling Excess Pore Pressure and Deformation on Nonlinear Seismic Soil Response. Acta Geotechnica, 11:191-207.

Özener, P.T, Özaydın, K., Berilgen, M.M., 2009. Investigation of Liquefaction and Pore Water Pressure Development in Layered Sands. Bulletin of Earthquake Engineering, 7:199-219.

Phillips, C., Hashash, Y.M., 2009. Damping Formulation for Nonlinear 1D Site Response Analyses. Soil Dynamics and Earthquake Engineering, 29:1143-1158.

Sassa, S., Takagawa, T., 2019. Liquefied Gravity Flow-Induced Tsunami: First Evidence and Comparison from the 2018 Indonesia Sulawesi Earthquake and Tsunami Disasters. Landslides, 16:195-200.

Sato, K., Kokusho, T., Matsumoto, M., Yamada, E., 1996. Nonlinear Seismic Response and Soil Property During Strong Motion. Soils and Foundations, 36:41-52.

Seed, H.B., Idriss, I.M., 1967. Analysis of Soil Liquefaction: Niigata Earthquake. Journal of the Soil Mechanics and Foundations Division, 93:83-108.

$\mathrm{Su}, \mathrm{D} ., \mathrm{Ming}, \mathrm{H}$. Li, X., 2013. Effect of Shaking Strength on The Seismic Response of Liquefiable Level Ground. Engineering Geology, 166:262-271.

Taboada, V., Dobry, R., 1993. Experimental Results of Model No. 1 at RPI. In: Arulanandan K, Scott RF, Editors. Verification of Numerical Procedures for the Analysis of Soil Liquefaction Problems, Rotterdam, A.A. Balkema, pp. 3-18.

Taghavinezhad, M., Choobbasti, A., Farrokhzad, F., 2019. Effect of Liquefaction on Nonlinear Seismic Response in Layered Soils: A Case Study of Babol, North of Iran. European Journal of Environmental and Civil Engineering, 1-18.

Tokimatsu, K., Tamura, S., Suzuki, H., Katsumata, K., 2012. Building Damage Associated with Geotechnical Problems in the 2011 Tohoku Pacific Earthquake. Soils and Foundations, 52:956-974.

Vucetic, M., Dobry, R., 1986. Pore Pressure Build-Up and Liquefaction at Level Sandy Sites During Earthquakes. In: Research Rep. No. CE-86-3, Dept. of Civil Engineering, Rensselaer Polytechnic Institute, Troy, NY.

Yoshida, N., Tokimatsu, K., Yasuda, S. et al., 2001. Geotechnical Aspects of Damage in Adapazari City During 1999 Kocaeli, Turkey Earthquake. Soils and Foundations, 41:25-45.

Youd, T.L., Carter, B.L., 2005. Influence of Soil Softening and Liquefaction on Spectral Acceleration. Journal of Geotechnical and Geoenvironmental Engineering, 131:811-825.

Yuan, H., Yang, S.H., Andrus, R.D., Juang, C.H., 2004. Liquefaction-Induced Ground Failure: A Study of the Chi-Chi Earthquake Cases. Engineering Geology, 71:141-155.

Zeghal, M., Elgamal, A.W., 1994. Analysis of Site Liquefaction Using Earthquake Records. Journal of Geotechnical Engineering, 120:996-1017.

Zeghal, M., Elgamal, A.W., Parra, E., 1996. Identification and Modeling of Earthquake Ground Response-II. Site Liquefaction. Soil Dynamics and Earthquake Engineering, 15:523-547.

Zheng, W., Luna, R., 2011. Nonlinear Site Response and Liquefaction Analysis in the New Madrid Seismic Zone. Geotechnical and Geological Engineering, 29:463-475.

Zorapapel, G.T., Vucetic, M., 1994. The Effects of Seismic Pore Water Pressure on Ground Surface Motion. Earthquake Spectra, $10: 403-438$

\section{Appendix}

Arulmoli et al. (1992) was carried out resonant column (RC) tests to define dynamic properties of Nevada Sand. The soil's small strain shear modulus $\left(G_{0}\right)$ with mean effective stress $\left(p^{\prime}\right)$ are shown in Figure 14. From nonlinear regression analyses, power curve fit of the $G_{0}-p^{\prime}$ relationship was determined using Test no: 40-77 data, and related equation was proposed in Equation (4).

$$
G_{0}=7.67\left(p^{\prime}\right)^{0.5}, \mathrm{MPa}
$$




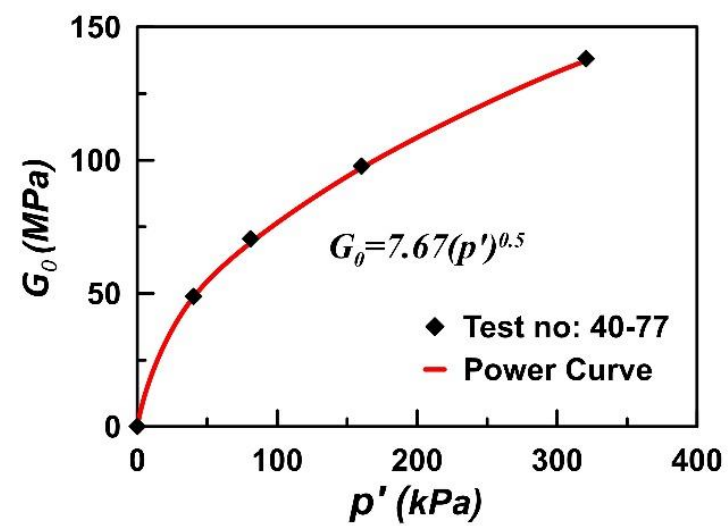

Figure 14. Power curve fit of the laboratory measurement used in Deepsoil simulations

Equation (4) was converted into $V_{s}$ formulation as a function of depth (z) as follows:

The small strain shear modulus of a soil can be obtained in terms of the shear wave velocity through the basic expression given in Equation (5).

$$
G_{0}=\rho\left(V_{s}\right)^{2}, \mathrm{kPa}
$$

here $\rho$ is soil mass density. Hereafter, Equation (4) and Equation (5) were equalized as shown in Equation (6).

$$
\rho\left(V_{s}\right)^{2}=7.67\left(p^{\prime}\right)^{0.5}
$$

From this condition, $V_{s}-z$ relationship given in Equation (1) obtained by combining Equations (7) and (8) in Equation (6).

$$
p^{\prime}=\frac{\sigma_{v}^{\prime}+2 \sigma_{h}^{\prime}}{3}
$$

where $\sigma_{v}^{\prime}$ is the effective vertical stress and $\sigma_{h}^{\prime}$ is the effective horizontal stress. $\sigma_{h}^{\prime}$ was rewritten in terms of $\sigma^{\prime}{ }_{v}$ using coefficient of lateral earth pressure at rest, $K_{0} . \sigma^{\prime}{ }_{v}$ was defined from Equation (8).

$$
\sigma_{v}^{\prime}=\left(\rho-\rho_{w}\right) g z
$$

where $\rho=1.96 \mathrm{t} / \mathrm{m}^{3}, \rho_{w}=1.0 \mathrm{t} / \mathrm{m}^{3}$, and $g$ is the gravity load. 